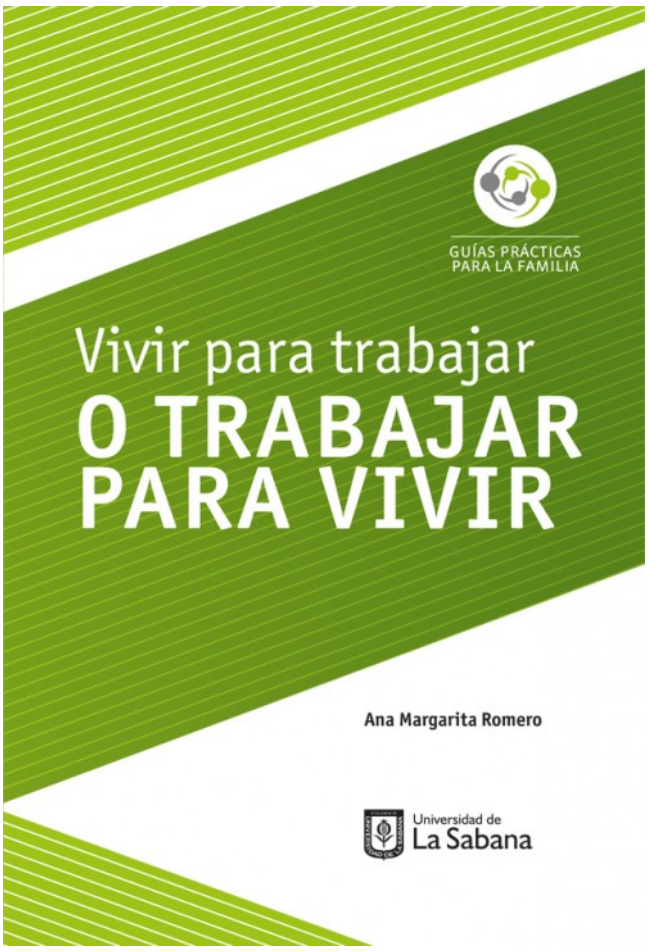

\title{
VIVIR PARA TRABAJAR O TRABAJAR PARA VIVIR
}

Por: Ana Margarita Romero

Formato: Impreso

ISBN: 978-958-12-0472-4

Facultad: Instituto de la Familia

Colección: Guías prácticas para la Familia

DOI: https://doi.org/10.5294/978-958-12-0472-4

Idioma: Español

Precio en dólares: USD $\$ 7,00$

Número de páginas: 72

Palabras clave: Familia, Trabajo, Trabajo y trabajadores, Vida familiar

$\$ 20.000$

\section{Reseña del Producto}

Con esta guía se pretende plantear una reflexión sobre algunos desafíos que las personas enfrentan en la actualidad en relación con su vida laboral, y cómo esto afecta sus relaciones familiares y, en ocasiones, incluso su sentido de vida. Se procura resolver algunas inquietudes con base en diferentes autores y respecto al significado del trabajo, al valor del desempeño profesional y al uso del dinero, así como a la relación que existe entre la familia y la economía.

\section{Información Adicional}

Peso: $1 \mathrm{~kg}$

Tamaño: $17 \times 24 \times 2 \mathrm{~cm}$

Sku: 9789581204724

Código topografico: 306.36

\section{Tabla de contenido}

INTRODUCCIÓN

VIDA FAMILIAR Y ECONOMÍA

¿Cómo influye la vida familiar en el trabajo?

¿Cómo se relaciona la economía con la familia?

NOCIONES SOBRE EL TRABAJO HUMANO

¿Qué es el trabajo?

¿Cuáles son las dimensiones

y clases de trabajo?

¿Cuál es el valor en el trabajo?

¿Cuál es el sentido atribuido al trabajo?

¿Cómo el valor del trabajo es fuente de santidad? 
DESAFÍOS PARA LA VIDA FAMILIAR 27

¿Qué tensiones experimentan los esposos por el trabajo del hogar y el profesional?

¿Cuáles son las funciones de la familia?

¿Qué estrategias educativas puedo implementar en la educación económica de los hijos?

¿Cuáles son algunas ideas para la educación de los hijos en el ámbito de la responsabilidad económica y financiera?

TRABAJO COMO FUENTE DE DESARROLLO PERSONAL

¿Cómo se articulan el éxito y la satisfacción laboral y personal?

¿Cómo aportan algunas virtudes como la laboriosidad, la generosidad y el servicio al trabajo?

¿Cómo se establecen prioridades?

VALORACIÓN DEL TRABAJO DEL HOGAR

¿En qué consiste el cuidado del hogar?

¿Por qué el trabajo del hogar es menos valorado?

¿Qué hace que las personas se estresen con relación al trabajo del hogar y el profesional?

VARIABLES IMPLICADAS EN EL TRABAJO

¿Cuáles son las claves para gestionar el tiempo?

¿Por qué el trabajo a veces es un factor estresante?

EL ÁMBITO EMPRESARIAL COMO ACTOR CLAVE PARA EL FORTALECIMIENTO FAMILIAR

¿Qué pueden hacer las empresas a fin de contribuir con la integración familia-trabajo?

¿Qué opciones existen con referencia a la flexibilidad laboral?

REFERENCIAS 